\title{
The effects of thyrotropin-releasing hormone and scopolamine in Alzheimer's disease and normal volunteers
}

\author{
Susan E. Molchan, Alan M. Mellow ${ }^{1}$, James L. Hill2, Herbert Weingartner ${ }^{3}$, \\ Rick Martinez, Benedetto Vitiello and Trey Sunderland \\ Unit on Geriatric Psychopharmacology, Laboratory of Clinical Science, National Institute of Mental Health, Bethesda, MD, \\ ${ }^{1}$ Department of Psychiatry, University of Michigan, Ann Arbor, MI, ${ }^{2}$ Unit on Biostatistics, Laboratory of Clinical Science, \\ National Institute of Mental Health, Bethesda, MD and ${ }^{3}$ Section on Cognitive Neurosciences, National Institute of Alcoholism \\ and Alcohol Abuse, Bethesda, MD, USA
}

Thyrotropin-releasing hormone (TRH), a neuromodulator and possibly a neurotransmitter in the central nervous system, was shown in a prior study of young normal volunteers to attenuate the memory impairment induced by the anticholinergic drug scopolamine. In the present study, the cognitive, behavioral and physiologic effects of high dose TRH $(0.5 \mathrm{mg} / \mathrm{kg})$, both alone and following administration of scopolamine, were examined in 10 Alzheimer's disease ( $\mathrm{AD}$ ) patients (mean age $\pm \mathrm{SD}=63.5$ years) and 12 older normal volunteers (mean age $=64.9 \pm 8.8$ years). On the day $\mathrm{AD}$ subjects received TRH alone, modest but statistically significant improvement from baseline performance was documented on some tests of learning and memory, especially in those with mild dementia severity. In comparing cognitive test performance between the scopolamine alone and scopolamine+TRH conditions, only two test scores were significantly higher in the latter condition. In the group of older volunteers, TRH did not attenuate scopolamine-induced cognitive impairment, contrary to prior findings in a group of younger controls. In fact, older subjects performed worse after receiving scopolamine followed by TRH than after receiving scopolamine alone. In addition, no change from baseline cognitive performance was detected after subjects received TRH alone. These findings raise several questions and speculations on possible age-related changes in the cholinergic system, as well as on the mechanism of the interaction of TRH with the cholinergic system.

Key words: thyrotropin-releasing hormone (TRH); neuropeptide; scopolamine; memory; Alzheimer's disease; ageing

\section{Introduction}

The tripeptide thyrotropin-releasing hormone (TRH) has been proposed to have potential therapeutic value in Alzheimer's disease (AD) (Yarbrough, 1979; Metcalf, 1982). This proposal arises from the fact that TRH and TRH analogs have been shown, in animal studies, to have positive neuromodulatory effects on the cholinergic system (Breese et al., 1975; Yarbrough, 1979; Horita, Carino and Lai, 1986; Suzuki et al., 1989; Hutson, Semark and Middlemeiss, 1990; Okada, 1991) and to facilitate memory and learning in animal paradigms used to model the memory impairment of $\mathrm{AD}$ [e.g. after administration of the centrally active anticholinergic drug scopolamine (Yamazaki, Nagaoka and Nagawa, 1986; Yamamura et al., 1991) or lesions of the septohippocampal system (Horita et al., 1989; Yamamura et al., 1991)]. In addition, areas of the brain thought to be involved in learning and memory, the amygdala, hippocampus and temporal cortex, have high concentrations of TRH receptors (Manaker et al., 1986). It has been questioned, though, whether sufficient quantities of a peptide such as TRH could be delivered across the bloodbrain barrier to the brain (Metcalf, 1982).

In a previous study, we administered intravenously high doses of TRH $(0.5 \mathrm{mg} / \mathrm{kg})$ to young normal volunteers and were able to demonstrate an attenuation of some of the cognitive impairment induced by the anticholinergic drug scopolamine (Molchan et al., 1990). The scopolamine model of geriatric memory dysfunction is widely employed experimentally (Drachman and Leavitt, 1974; Bartus et al., 1982; Sunderland et al., 1986), and some pharmacological agents that reverse scopolamine-induced cognitive impairment have been shown to be of modest benefit to memory performance of elderly subjects as well as of some patients with AD (Drachman, 1977; Sitaram, 
Weingartner and Gillin, 1978; Mewaldt and Ghoneim, 1979; Mohs et al., 1985).

Given our previous experience with TRH in young normals (Molchan et al., 1990), and two prior studies in AD subjects using lower doses of TRH (Mellow et al., 1989; Lampe et al., 1990), we sought to examine the cognitive, behavioral and physiologic effects of high dose $\mathrm{TRH}$ in a group of patients with $\mathrm{AD}$ and in older normal volunteers. In addition, we hoped to learn about the modulatory effects of TRH on responses to scopolamine in these subject groups.

\section{Methods}

\section{Subjects}

Ten AD patients (four females and six males; mean age $\pm S D=63.5 \pm 7.8$ years) and 12 normal volunteers (three females and nine males; mean age $\pm \mathrm{SD}=64.9 \pm 8.8$ years) participated in the study after informed consent and screening which excluded any medical or psychiatric illness (Table 1). Probable AD was diagnosed according to ADRDA/NINCDS criteria (McKhann et al., 1984). Dementia severity was assessed by staff members during the inpatient admission in which they participated in the protocol, using the Global Deterioration Scale (GDS) (Reisberg et al., 1982). All subjects were drug-free for at least 3 weeks prior to the study. Normal volunteers were paid for their participation.

\section{Experimental design}

After the baseline cognitive battery, subjects participated in three study days, each separated by at least $72 \mathrm{~h}$. On each study day, beginning at about 8:30 a.m. an indwelling i.v. catheter was inserted and scopolamine hydrobromide ( $0.25 \mathrm{mg}$ for $\mathrm{AD}$ patients and $0.5 \mathrm{mg}$ for normals) or placebo was administered, followed by either high dose TRH $(0.5 \mathrm{mg} / \mathrm{kg})$ or placebo $45 \mathrm{~min}$ later. Drugs and placebos were administered in a double-blind, randomized manner. Cognitive testing was done on each study day $45 \mathrm{~min}$ after administration of TRH/placebo, i.e. $90 \mathrm{~min}$ after scopolamine/placebo administration. Prior studies

Table 1 Clinical characteristics of older normal volunteers and Alzheimer's patients

\begin{tabular}{lcc}
\hline Variable & Volunteers $(n=12)$ & Alzheimer's $(n=10)$ \\
\hline Age (years) & $64.9 \pm 8.8$ & $63.5 \pm 7.8$ \\
Gender & $3 \mathrm{~F}, 9 \mathrm{M}$ & $4 \mathrm{~F}, 6 \mathrm{M}$ \\
Weight $(\mathrm{kg})$ & $68.9 \pm 10.5$ & $67.8 \pm 9.7$ \\
Education (years) & $17.8 \pm 1.6$ & $16.9 \pm 4.2$ \\
WMS score $^{\text {a }}$ & $131.1 \pm 15.0$ & $72.2 \pm 16.1$ \\
GDS $^{\mathrm{b}}$ score & & $4.3 \pm 0.7$
\end{tabular}

Numbers are mean \pm SD

aWechsler Memory Scale. "Global Deterioration Scale. in humans have shown that the cognitive effects of i.v. scopolamine peak from 90 to $150 \mathrm{~min}$ after administration (Safer and Allen, 1971), and that central effects of high-dose TRH occur between 30 and $90 \mathrm{~min}$ after infusion (Mellow et al., 1989; Molchan et al., 1990).

Behavioral ratings and digit span testing were performed by the physician investigator at four time points on each study day, prior to, and 30,60 and $135 \mathrm{~min}$ after scopolamine/placebo administration. Behavioral ratings included two visual analog scales (VAS), which range from 0 to $100 \mathrm{~mm}$, and the NIMH behavioral rating scale (which ranges from 0 or 'not present' to 6 or 'very marked') and symptom checklist (which ranges from 0 or 'none' to 3 or 'much') (van Kammen and Murphy, 1975). An automated vital signs monitor (Critikon Inc., Tampa, FL) recorded blood pressure (BP) and heart rate, and oral temperature was recorded on each study day $15 \mathrm{~min}$ and just prior to administration of scopolamine or placebo (time 0 ), and $30,45,60,90$ and $135 \mathrm{~min}$ thereafter.

To obtain central cognitive effects, we administered a very high dose of TRH since it crosses the blood-brain barrier poorly (Metcalf, 1982), and is quickly metabolized, having a plasma half-life of only 4-5 min (Bassiri and Utiger, 1973). The dose of TRH was chosen based on results from previous studies in which cognitive effects were demonstrated using similar doses (Mellow et al., 1989; Molchan et al., 1990). In addition, significantly elevated levels of CSF TRH have been documented 120 min after peripheral administration of high doses of the peptide (Mitsumoto et al., 1986). TRH was purchased from Peninsula Laboratories (Belmont, CA) and analyzed for purity by the NIH Pharmaceutical Development Service.

The dose of scopolamine used in the AD group was chosen based on results from a prior study which showed that after $0.25 \mathrm{mg}$, side effects are tolerable such that cognitive testing can usually be completed, with a significant decline in cognitive performance demonstrated (Sunderland et al., 1987). In the normal volunteers, the dose was chosen based on a prior study of a range of scopolamine doses which showed that statistically significant decreases in cognitive test performance in older normal volunteers occur at the $0.5 \mathrm{mg}$ dose (Sunderland et al., 1987).

Note that no placebo/placebo day was included in the study design, which was established primarily to compare performance among drug conditions. No statistically significant differences between performance on similar cognitive test batteries administered at baseline, prior to a subject's participation in drug studies, and cognitive performance during placebo conditions had been shown in 14 young normal volunteers (Sitaram, Weingartner and Gillin, 1978) and 11 AD patients (Tariot et al., 1987) by ANOVA. Retrospective analysis of variance (ANOVA) 
of data from another study, of $10 \mathrm{AD}$ patients and 10 older controls, also showed no differences between baseline and placebo day cognitive performance. These data were collected in conjunction with a study examining the effects of a range of scopolamine doses in those subjects (Sunderland et al., 1987); it was not included in that report but the data are available on request. In addition, no differences have been shown between tests of memory and information processing done prior to drug administration (time 0 ) and after administration of placebo (Wesnes and Warburton, 1984; Sunderland et al., 1987). For these reasons the cognitive test results from the baseline day were included in some statistical analyses as noted below. In addition, it seemed that the advantage of having a true placebo day would be negligible in that prior studies have shown that the side effects of scopolamine and TRH are such that the blindness of placebo versus scopolamine or TRH conditions would be compromised (Sunderland et al., 1987; Mellow et al., 1989).

\section{Cognitive tests}

Subjects were administered a baseline cognitive battery that included the Wechsler Memory Scale (WMS) (Wechsler, 1945) and tests of attention, memory and learning. Tests were administered in the same order on each study day, beginning with the vigilance task, followed by category retrieval and then the selective reminding test. For the normal volunteer group, a continuous performance task (CPT) was administered at the end of the test session. Digit span was tested four times during each study day, in conjunction with behavioral ratings. Descriptions of the tests have been published previously (Sunderland et al., 1987) and are summarized below.

\section{Vigilance task}

Subjects were read a list of 12 categorically related words, six of which were repeated; subjects were instructed to signal the examiner upon hearing a word for the second time as a measure of vigilance-attention. The number of correctly identified words that had been heard twice (a maximum of six words) was recorded as the score. Subjects were later asked to freely recall items from the list. Subjects were then read a list of 24 words, 12 of which were from a previously presented list (where six had been presented once and six had been presented twice), and 12 completely new words. Accuracy of the recognition of words that had been presented previously (either once or twice) was recorded as a measure of recognition memory. As words were recognized, subjects were asked to recall how frequently a word had been presented (once or twice). The difference between the mean reported frequency of the once-presented and twicepresented words was used as a measure of automatic memory processes (Hasher and Zacks, 1979).

\section{Category retrieval}

As a measure of retrieval from knowledge memory, subjects were given two letters and asked to generate words beginning with those letters. They were then given words representing a broad category and asked to generate related words (Battig and Montague, 1969). Responses were recorded over a 90 s period.

\section{Selective reminding test}

As a test of episodic learning and memory, subjects were read a list of six categorically unrelated words and were asked to recall them; missed words were repeated by the examiner and recall was attempted again. This process was repeated for a total of eight trials. A free recall score and a consistency of recall score were recorded (Buschke, 1973).

\section{Continuous performance task}

As a measure of choice reaction time, a CPT was administered to the group of normal volunteers. During the approximately $8 \mathrm{~min}$ of this test, subjects were instructed to attend to a screen on which 1, 3 or 6 letters appeared, for a period of 1,3 or $6 \mathrm{~s}$, respectively. Following this exposure, a single letter appeared, and subjects were instructed to press a button labeled 'yes' if the letter had been displayed previously, or a button labeled 'no' if it had not. The times between stimulus presentation and correct response for each trial were averaged to obtain the mean reaction time; accuracy was recorded as the percentage of correct responses.

\section{Digit span}

Subjects were read random sequences of digits and were asked to recall them immediately, in either the sequence as given (forward) or in backwards order.

\section{Statistical analysis}

Cognitive data from the three drug conditions were analyzed by one-way repeated measures ANOVA accompanied by $a$ priori contrasts between the scopolamine and scopolamine + TRH conditions. In all analyses, the data met the assumption of homogeneity of covariance; therefore corrections for lack of homogeneity were not applied. The ANOVA was also carried out with the baseline condition included, as noted above in the explanation of the experimental design, with accompanying $a$ priori contrasts between baseline and scopolamine alone, scopolamine and scopolamine + TRH, 
and baseline and TRH alone. One-tailed probabilities were used with the analysis of the AD data, based on the hypothesis that TRH would improve cognitive function and on evidence from prior studies that it does so, including two studies of AD patients (Yamazaki, Nagaoka and Nagowa, 1986; Horita et al., 1989; Mellow et al., 1989; Lampe et al., 1990; Molchan et al., 1990). Two-tailed probabilities were used for the normal volunteer data. A binomial (signed rank) test was also performed to compare cognitive test scores after scopolamine and after scopolamine + TRH in the normals.
ANOVA was also used to check for carry-over or order effects of drug administration.

Behavioral data from the VAS were analyzed using repeated measures ANOVA to evaluate both of the within-subject variables of drug condition and time simultaneously, with a priori contrasts between study days. One-tailed probabilities were used to maximize detection of the described analeptic effect of TRH (Breese et al., 1975; Horita, Carino and Lai, 1986; Mellow et al., 1989) on measures of alertness, concentration and drowsiness. The maximum change from baseline values

Table 2

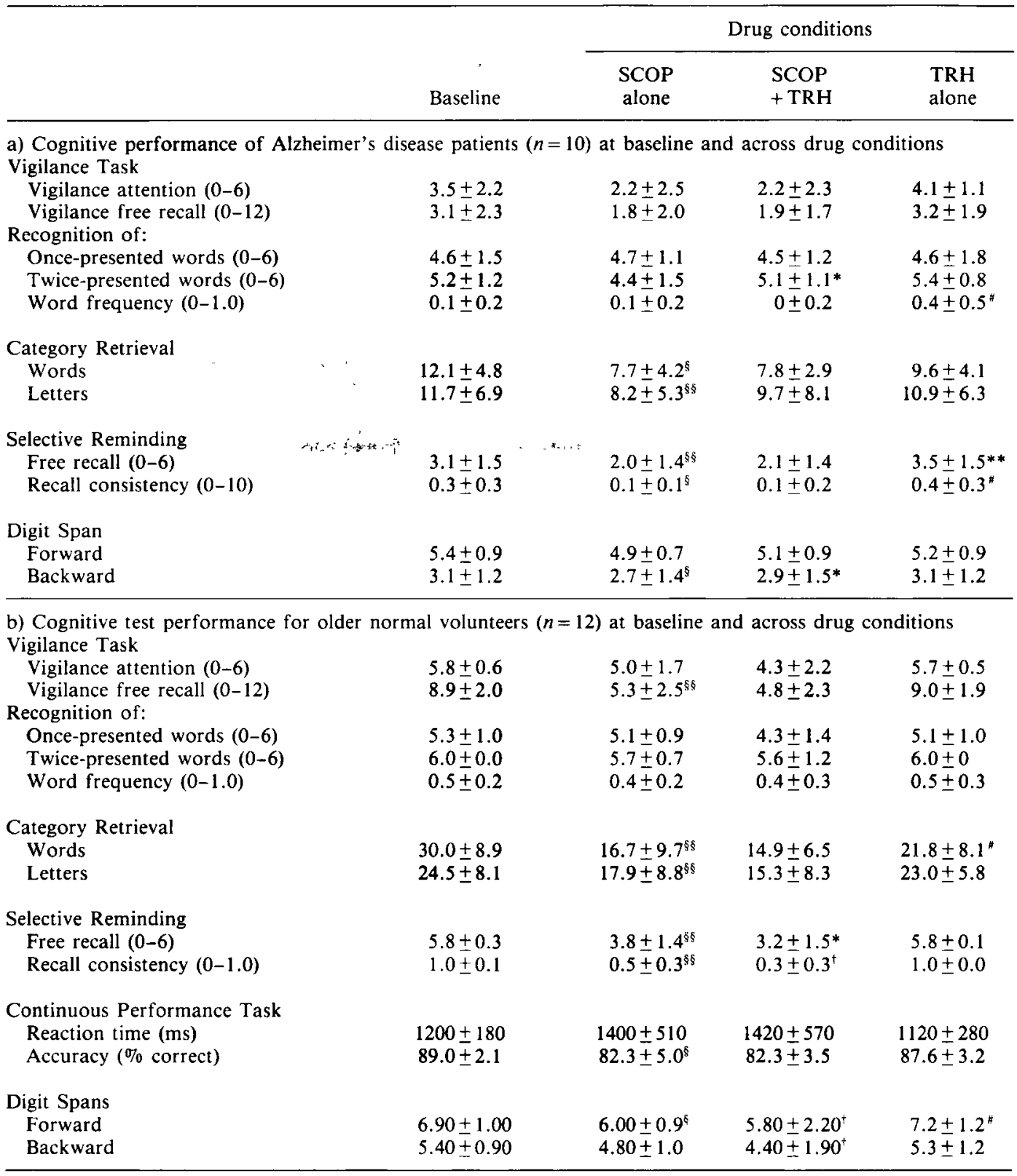

Scores presented as mean \pm SD. SCOP $=$ scopolamine. Numbers in parentheses include the range of test scores. ${ }_{p} p<0.05,{ }^{\S} p<0.005$, for comparison between baseline and scopolamine conditions.

${ }^{*} p<0.05,{ }^{t} p<0.1$, for comparison between scopolamine and scopolamine + TRH conditions.

${ }^{* *} p<0.05, " p<0.1$, for comparison between baseline and TRH conditions. 
(max delta) for each variable on each study day was evaluated for statistical significance using paired $t$-tests. Max deltas between the scopolamine and scopolamine + TRH conditions and the scopolamine + TRH and TRH conditions were compared using repeated measures ANOVA accompanied by a priori contrasts. Possible relationships between cognitive test scores and the VAS behavioral measures of alertness and drowsiness that were recorded just prior to cognitive testing were examined using Pearson's product-moment correlations (Winer, 1982).

Physiologic data were analyzed using one-way repeated measures ANOVA, and paired $t$-tests (two-tailed) to detect significant changes from baseline measures within each drug condition. The maximum increase in each parameter for each drug condition was compared using repeated measures ANOVA accompanied by a priori contrasts between the scopolamine and scopolamine + TRH conditions, and the scopolamine + TRH and TRH conditions.

\section{Results}

\section{Cognitive tests-Alzheimer's patients}

Mean scores for each of the tests under the various study conditions are summarized in Table $2 \mathrm{a}$. A significant decrease from baseline performance on several cognitive tests occurred after subjects received scopolamine alone, consistent with findings from prior studies (Sunderland et al., 1987). During the scopolamine + TRH condition, recognition of twice-presented words and backward digit span were better as compared with scopolamine alone; $[F(1,9)=3.8, p<0.05]$ and $[F(1,9)=5.6, p<0.02]$, respectively (Table $2 \mathrm{a}$ ); other test scores were unchanged. Results for the comparison between the scopolamine and scopolamine + TRH conditions were the same whether the results from the baseline day were included in the ANOVA or not. Cognitive performance improved significantly from baseline after TRH on the selective reminding task and at a trend level of significance on the estimation of word frequency, used as a measure of automatic processing (Table $\mathbf{2 a}$ ).

For the subjects with the highest WMS scores, and whose dementia severity was mild to moderate, as rated by the GDS, performance improved on more tests, and to a greater degree, than performance in the overall group after TRH administration. Test scores for which improvement was demonstrated in this subgroup are depicted in Fig. 1 and included: selective reminding test free recall $[F(1,3)=4.3, p<0.05]$, selective reminding test recall consistency $[F(1,3)=10.3, p<0.03]$, automatic processing $[F(1,3)=5.5, p<0.05]$ and free recall of twice-presented words $[F(1,3)=6.0, p<0.05]$.

No significant correlations were found between performance on the selective reminding test and the VAS

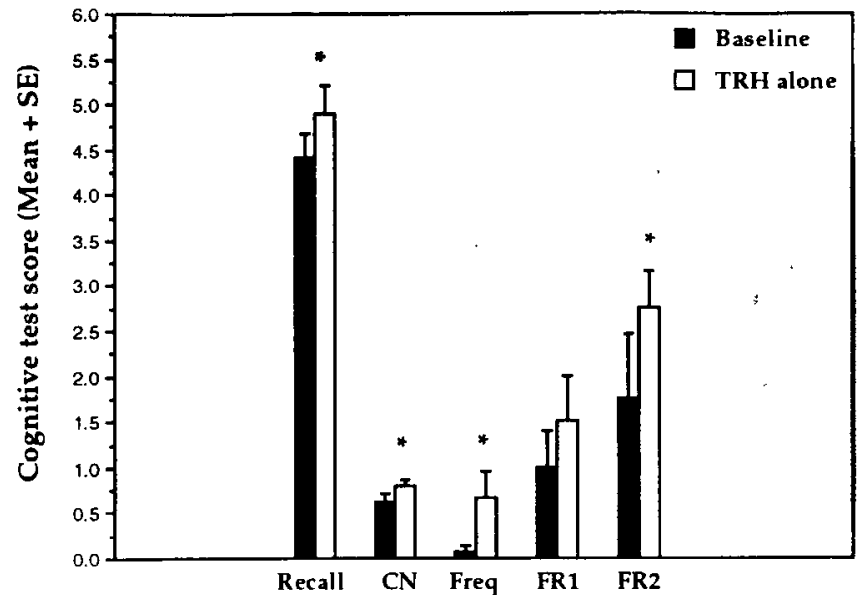

Figure 1 Cognitive test scores (mean $+\mathrm{SE}$ ) are represented for the four AD subjects with the highest WMS scores, comparing individual cognitive tests at baseline with scores after high dose TRH administration. Tests depicted in the graph, from left to right, are selective reminding test free recall (Recall), selective reminding test consistency $(\mathrm{CN})$, a measure of automatic processing (Freq), free recall of once-presented words (FR1) and free recall of twice-presented words (FR2). ${ }^{*} p<0.05$

behavioral measures of alertness and drowsiness in the overall group of subjects. Significantly, there were no carry-over effects, or effects of the order of drug administration as detected by ANOVA.

\section{Normal subjects}

Table $2 b$ summarizes the mean scores for each of the cognitive tests under the various study conditions. As expected, cognitive performance declined significantly after administration of scopolamine alone, with either no change or further decline on some tests after scopolamine + TRH. After administration of TRH alone, a significant decline in score was measured on the word category retrieval test and on recognition of words that had been presented once (Table 2b). Drug-induced alterations in test scores were consistent for the individual subjects, i.e. there were no outliers. In addition, no carryover or order effects were detected. No test score increased during the scopolamine $+\mathrm{TRH}$ as compared with the scopolamine alone condition. Scores were significantly lower during the scopolamine $+\mathrm{TRH}$ condition as compared with scopolamine alone $(p<0.001)$ using the binomial test. No significant correlations were found between selective reminding test scores and behavioral measures of alertness and drowsiness.

To examine whether age may have affected cognitive testing or drug response, the group was divided into those $\leqslant 65(n=5)$ and those $>65(n=7)$, and $t$-tests were used to compare cognitive tests scores during each of the drug conditions between these two subgroups. Baseline scores 


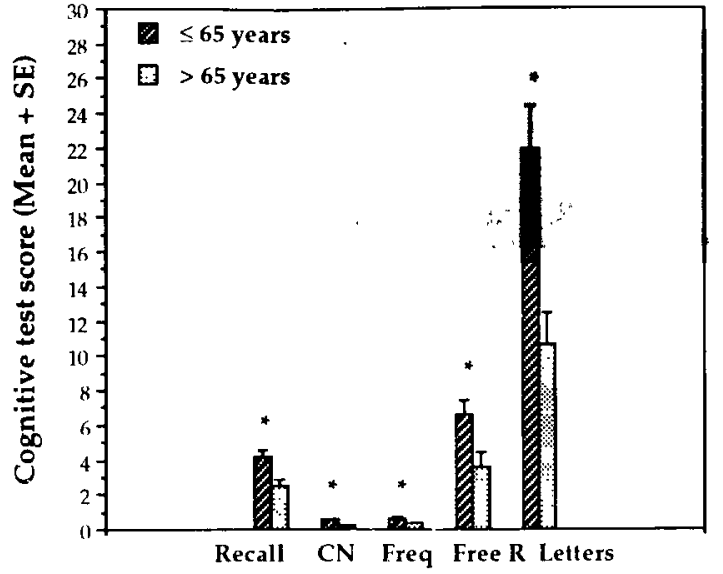

Figure 2 Cognitive test scores (mean $+\mathrm{SE}$ ) during the scopolamine + TRH condition for which a significant difference was found between normal volunteers $>65$ and $\leqslant 65$ years old. Tests depicted are as in Fig. 1, with the addition of a total free recall score (Free $\mathrm{R}$ ) from the vigilance task, and letter fluency score (Letters). ${ }^{*} p<0.05$ and scores after scopolamine alone did not differ significantly between the two subgroups. The older subjects' scores were lower than the relatively younger subjects' on most of the tests during the scopolamine + TRH condition. This difference was significant for selective reminding free recall $(t=-2.23,10 \mathrm{~d} . \mathrm{f}$., $p<0.05)$, selective reminding consistency $(t=-2.24$, 10 d.f., $p<0.05)$, word frequency $(t=-2.3,10$ d.f., $p<0.04$ ), total free recall of the words from the vigilance task $(t=-2.9,10$ d.f., $p<0.01)$, and letter fluency $(t=-3.1,10$ d.f., $p<0.01$ ) (Fig. 2).

\section{Behavioral measures-Alzheimer's patients}

Results for VAS behavioral data comparing drug conditions as analyzed by repeated measures ANOVA and using max deltas were similar; the max delta data are summarized in Table 3. No differences from baseline were detected on the day subjects received TRH alone (Table 3).

Table 3 Comparison of maximum changes from baseline of behavioral effects (as evaluated by visual analog scales) across baseline and three drug conditions in Alzheimer's patients $(n=10)$ and normal volunteers $(n=12)$

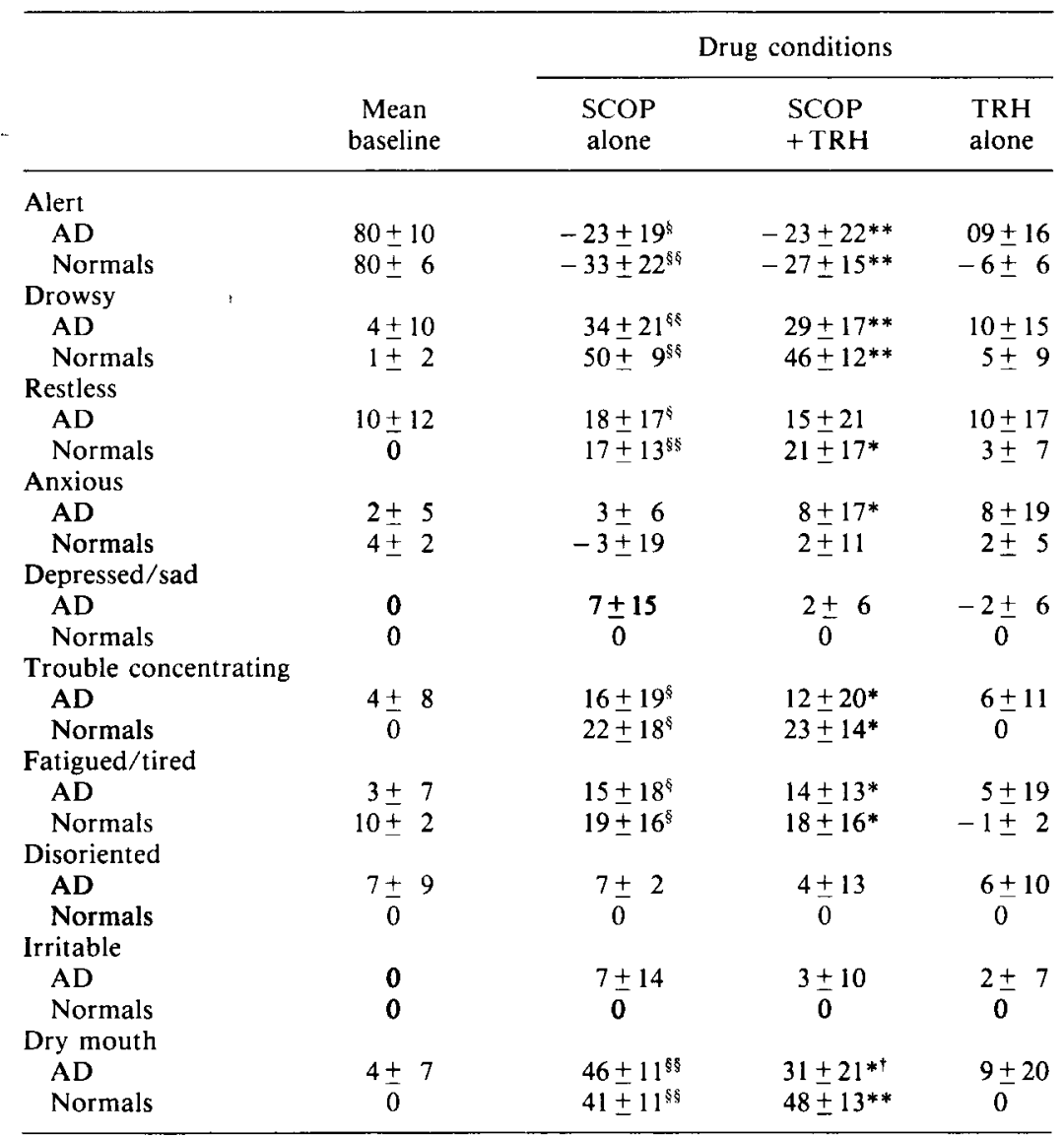

Scores are expressed as mean $\pm \mathrm{SD}$. SCOP $=$ scopolamine.

${ }^{\S} p<0.05,{ }^{\S} p<0.001$ for baseline compared with scopolamine.

${ }^{*} p<0.05,{ }^{* *} p<0.001$, for baseline compared with scopolamine $+\mathrm{TRH}$.

${ }^{+} p<0.02$ different from scopolamine alone. 
None of the subjects became delusional or experienced hallucinations during any of the study days. Besides those included in Table 3, physical side effects, as evaluated using VAS and the NIMH scale, included slightly blurred vision in three patients after scopolamine, a shivering response lasting about $10 \mathrm{~min}$ after TRH administration in all, a brief urge to micturate in three patients after TRH and one after scopolamine, and an unusual taste in three patients after TRH administration.

\section{Normal subjects}

Behavioral data are summarized in Table 3; results were similar to those of the AD group.

\section{Physiological measures-Alzheimer's patients}

Physiologic data are represented graphically in Fig. 3. In comparing the maximum increases from baseline values among drug conditions, significant differences were found between scopolamine and scopolamine + TRH for systolic $\mathrm{BP}[F(1,9)=5.8, p<0.04]$, diastolic $\mathrm{BP}[F(1,9)=$ $6.3, p<0.03]$ and temperature $[F(1,9)=6.3, p<0.04]$. The mean maximum increases from baseline in systolic and diastolic BP, heart rate and temperature were greater after administration of TRH alone as compared with scopolamine $+\mathrm{TRH}$, but the differences were not statistically significant.

\section{Normal subjects}

Figure 3 summarizes the physiologic data. The only measure showing a significant difference in maximum increase from baseline between drug conditions was systolic BP, in the comparison between scopolamine and scopolamine + TRH $[F(1,11)=19.9, p<0.001]$.

\section{Discussion}

In a prior study, we showed that TRH attenuated the cognitive impairment associated with scopolamine administration in young normal volunteers (Molchan et al., 1990). Since the cognitive effects of scopolamine in older normals have been compared to the cognitive profile of $\mathrm{AD}$ patients, we expected that administration of TRH may lead to improved cognitive performance in $A D$ subjects. However, after TRH administration to $10 \mathrm{AD}$ patients, mean scores improved significantly from baseline only on the selective reminding test, a measure of new learning and memory. The cognitive performance of the four subjects with the highest WMS scores improved to a greater degree and on a larger number of cognitive tests than the overall group (Fig. 1), indicating that the brains of these less impaired subjects were better able to respond to the intervention than the more severely demented patients.

TRH attenuated the cognitive effects of scopolamine only on a recognition memory test and backward digit span (Table 2a). In the prior study of young normal volunteers, TRH attenuated the effects of scopolamine on a larger number of tests (Molchan et al., 1990). Presumably, this would be due to the inability of already compromised cholinergic systems in the $\mathrm{AD}$ subjects to recover from the additional anticholinergic, cognitionimpairing effects of scopolamine.

The effects of TRH in older normal volunteers were somewhat anomalous, in that their cognitive performance decreased after the addition of TRH to scopolamine, with no change or a decrease from baseline scores after administration of high dose TRH alone (Table 2b). This differs from findings in young normal volunteers and animal studies, in which TRH and TRH analogs attenuate scopolamine-induced cognitive impairment (Yamazaki, Nagaoka and Nagawa, 1986; Horita et al., 1989; Molchan et al., 1990; Yamamura et al., 1991). In the comparison of cognitive test results of those less than or equal to 65 and those over 65 , several test scores during the scopolamine + TRH condition (and not at baseline or the other drug conditions) were significantly lower in those over 65 as compared with the relatively younger group. This decrease is different from results in the prior study of young volunteers (Molchan et al., 1990) and cannot be explained by baseline differences, as baseline cognitive performance between the two groups was not significantly different, as assessed by $t$-tests (unpublished data). The cognitive findings in older volunteers also contrast with those of AD patients, though results from the two groups are not directly comparable as they received different doses of scopolamine.

The contrasting findings between the previous study in young normal volunteers (Molchan et al., 1990) and the present results in older normals raise several questions and speculations on possible differences in pathophysiologic changes which occur in the cholinergic system with age and in $\mathrm{AD}$, as well as on the mechanisms of interaction between TRH and the cholinergic system in older, as compared with younger, subjects. The most consistently demonstrated findings in the cholinergic system that occur in the aged brain are decreased acetylcholine $(\mathrm{ACh})$ synthesis (Gibson, Peterson and Jenden, 1981; Decker, 1987), decreased ACh release (Decker, 1987; Wu et al., 1988) and decreased responsivity of cholinergic neurons to ACh (Bartus et al., 1982; Lippa et al., 1985; Decker, 1987). Theories as to the mechanism by which TRH may interact with the cholinergic system to improve cognitive performance in scopolamine-treated young human subjects and animals, in animals with septo-hippocampal lesions and in patients with $\mathrm{AD}$ include: (1) an increase in the synthesis (Narumi et al., 
S. E. MOLCHAN et al.
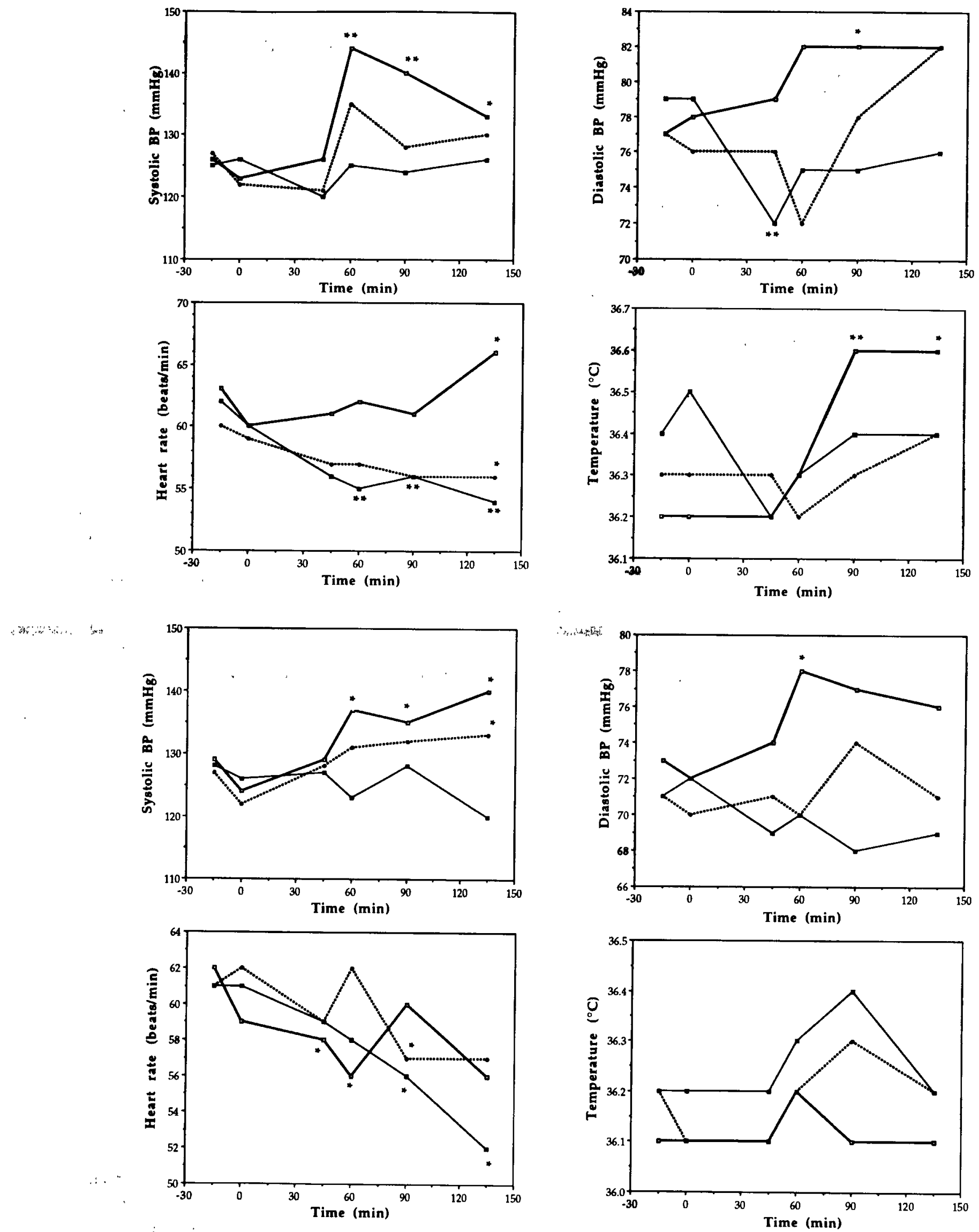
1983) and/or release of ACh (Suzuki et al., 1989; Hutson, Semark and Middlemeiss, 1990; Okada, 1991); (2) an increase in $\mathrm{ACh}$ receptor sensitivity (Winokur and Beckman, 1978) (though this has not been observed by some investigators); and (3) direct excitation of cerebral cortical (Lamour, Dutar and Jobert, 1983) and septohippocampal neurons (Lamour et al., 1989). A direct action of TRH at the cholinergic receptor has not been demonstrated. In that TRH has been shown to facilitate $\mathrm{ACh}$ release, and $\mathrm{ACh}$ availability and release may be impaired with ageing (Decker, 1987; Wu et al., 1988), the most likely explanation for the differential effects of scopolamine + TRH in older and younger subjects may be decreased release of ACh by TRH in the older subjects.

An additional change shown to occur with age in several animal and human studies is that with increasing age there is a loss of muscarinic receptors in the cerebral cortex (White et al., 1977; Perry, 1980; Nordberg and Winblad, 1981; Rinne, 1987; Pedigo, 1988; Schwarz et $a l ., 1990)$. Some animal studies have shown that this loss is due primarily to a decrease in the density of type 1 muscarinic (M1) receptors (Pedigo, 1988; Schwarz et al., 1990). In contrast, in AD a decrease in the density of type 2 muscarinic (M2) receptors has been documented, with that of Ml receptors remaining relatively intact (Mash, Flynn and Potter, 1985; Araujo et al., 1988; Lange et al., 1990).

Speculatively, our data may suggest that scopolamine, which blocks M1 receptors with significantly higher affinity than M2 receptors (Burke, 1986), may therefore allow the autoregulatory pre-synaptic $\mathrm{M} 2$ receptors to decrease ACh release, especially in older normals who may have fewer M1 and relatively intact numbers of M2 receptors in the first place (Pedigo, 1988; Schwarz et al., 1990). Possibly, because of this or other age-related changes, the facilitatory effect of TRH on the cholinergic system may not occur in normal older subjects as it apparently did in younger subjects (Molchan et al., 1990). Instead, a functionally inhibitory effect on cholinergic transmission may occur. If TRH is acting in our paradigm to increase the effects of $\mathrm{ACh}$, this explanation may be consistent with differential findings between age groups in a recent animal study in which performance of old but not young rats on a test of spatial reference memory declined after acute treatment with an M1 cholinergic agonist, though subsequently improved after more chronic treatment (Brandeis et al., 1990).

It should also be noted that alterations in other neurotransmitter systems that occur with age may impact on cholinergic system responsivity and on memory performance (Thompson et al., 1984; Zornetzer, 1986; Marcyniuk, Mann and Yates, 1989; Wenk et al., 1989), and that TRH affects some of these systems, most notably the noradrenergic and dopaminergic (Metcalf, 1982; Horita, Carino and Lai, 1986). We cannot rule out, and acknowledge that it is likely, that neurotransmitter or neuromodulator systems besides the cholinergic contributed to the effects of TRH. If other systems such as the noradrenergic are facilitated (Horita, Carino and Lai, 1986), the rationale for the use of TRH for AD patients is strengthened, in view of the documented deficits in a number of neurotransmitter systems in this disease (Price, 1986; Zweig et al., 1988).

The question of whether behavioral side effects may have influenced cognitive test performance after the administration of scopolamine and TRH recurs in every study that utilizes these agents. TRH has analeptic effects (Breese et al., 1975; Horita, Carino and Lai, 1986; Mellow et al., 1989) which could conceivably contribute to its attenuation of some of the effects of scopolamine, which usually causes some drowsiness. The analeptic effect does not seem to be a factor in the present study, as shown by the lack of significant change on the measure of vigilance-recognition, forward digit span and CPT in the normals (Table $2 b$ ), which were used as measures of attention, and the lack of significant correlations between cognitive test scores and measures of drowsiness and alertness on the day subjects received TRH. Moreover, on the day subjects received $\mathrm{TRH}$, there were no differences from baseline in alertness, drowsiness and other behavioral measures, nor were there significant differences on these parameters between the scopolamine and scopolamine + TRH conditions (Table 3). In addition, in a recently completed study of young normal volunteers, we found that the stimulant dextroamphetamine did not attenuate the cognitive effects of scopolamine (Martinez et al., in preparation).

It should be emphasized that, although high dose TRH has side effects, such as the shivering response, these are transient, so that, by the time of cognitive testing, the blindness (as to whether TRH or placebo may have been administered) of the person administering the cognitive tests was not compromised. Also, subjects were unaware of the cognitive response expected after TRH administration.

The changes in systolic BP recorded in this study (Fig. 3) were consistent with findings from prior studies showing a marked pressor effect of TRH (Horita,

Figure 3 Effects of scopolamine alone, scopolamine + TRH, and TRH alone on blood pressure, heart rate, and temperature in AD (upper four graphs) and normal subjects (lower four graphs) across time. ${ }^{*} p<0.05,{ }^{* *} p<0.01$ for comparisons with baseline values within each study day. Scopolamine or placebo was administered at time 0 , and TRH or placebo at time +45 . - $-\mathrm{TRH}, \ldots \cdot \ldots$ Scop + TRH, —- - Scop 
Carino and Lai, 1986; Mellow et al., 1989; Molchan et $a l ., 1990)$, the etiology of which has been posulated to involve central muscarinic receptors (Horita, Carino and Lai, 1986; Mattila and Bunag, 1986; Okuda, Mizobe and Miyazaki, 1987; Brezenoff, Vargas and Xiao, 1988). The mean increases in BP, both systolic and diastolic, were highly variable, and greater on the day subjects received TRH alone as compared with the day they received scopolamine + TRH. These differences did not reach statistical significance, with the exception of systolic BP in the volunteers, which is consistent with cholinergic system involvement in the pressor response induced by $\mathrm{TRH}$ in that group. The observed increase in temperature is consistent with studies showing a thermogenic effect of TRH (Horita, Carino and Lai, 1986). The mean temperature increase was greater on the day subjects received TRH alone (Fig. 1) than on the day they received scopolamine + TRH, though the difference was not statistically significant.

In summary, high dose TRH modestly improved cognitive performance in a subgroup of mildly impaired patients with $\mathrm{AD}$. This finding is consistent with those of two prior studies which examined high dose TRH $(0.3 \mathrm{mg} / \mathrm{kg}$ i.v.) (Mellow et al., 1989) and high dose TRH (up to $12 \mathrm{mg}$ i.v.) in combination with lecithin (Lampe et al., 1990). These results suggest that further studies with TRH and TRH analogs, which are much more biologically stable than the native peptide as well as more accessible and specific to the central nervous system (Griffiths et al., 1989), may be warranted in patients with this illness. TRH analogs too, have been shown, in animal studies, to facilitate impaired memory performance to a greater degree than TRH itself (Yamazaki, Nagaoka and Nagawa, 1986; Yamamura et al., 1991). Also, like many peptides, TRH has been shown to exhibit trophic activity in the nervous system (Faden, Jacobs and Smith, 1984; Behbehani et al., 1990), and it has been hypothesized that trophic factors may be of benefit to patients with $\mathrm{AD}$ (Hefti, Dravid and Hartikka, 1984: Price, 1986).

Results in older volunteers in the present study were contrary to findings in a group of young controls, in whom an attenuation of scopolamine-induced cognitive impairment occurred after TRH administration, presumably by facilitating cholinergic system function (Molchan et al., 1990). These contrasting results suggest that the changes that occur in the brain with age, whether in receptor density, receptor sensitivity, second messenger systems or through some other mechanism, may change the response to this neuropeptide. The cognitive and physiologic responses reported in this study also differed from those reported in age-matched AD subjects and imply that some of the changes in neurochemical systems and mechanisms involved in the cognitive impairment which occur in normal ageing and in $\mathrm{AD}$ may be different. This remains a topic of some controversy
(Whitehouse and Au, 1986; Decker, 1987). Pharmacologic models similar to the one used in this study should be useful for further investigations of the neuromodulatory effects of peptides and the complex changes that occur with ageing and disease.

\section{Acknowledgements}

The authors wish to acknowledge Marcia Minichiello for her assistance with cognitive testing and data management, and the $6 \mathrm{~W}$ nursing staff for their continued support.

\section{Address for correspondence}

Dr Susan Molchan

NIH Clinical Center

9000 Rockville Pike

Building 10, Room 3D41

Bethesda

MD 20892

USA

\section{References}

Araujo D M, Lapchak P A, Robitaille Y, Gauthier S, Quirion R (1988) Differential alteration of various cholinergic markers in cortical and subcortical regions of human brain in Alzheimer's disease. J Neurochem 50: 1914-1923

Bartus R T, Dean RL, Beer B, Lippa A S (1982) The cholinergic hypothesis of geriatric memory dysfunction. Science 217: 408-417

Bassiri R M, Utiger R D (1973) Metabolism and excretion of exogenous thyrotropin releasing hormone in humans. $\mathrm{J}$ Clin Invest 52: 1616-1619

Battig W, Montague N (1969) Category norms for verbal items in 56 categories. J Exp Psychol Monogr 80: 1-43

Behbehani M M, Pun R Y K, Means E D, Anderson D K (1990) Thyrotropin-releasing hormone has profound presynaptic action on cultured spinal cord neurons. Synapse 6: 169-174

Brandeis R, Dachir S, Sapir M, Levy A, Fisher A (1990) Reversal of age-related cognitive impairments by an M1 cholinergic agonist, AF102B. Pharmacol Biochem Behav 36: 89-95

Breese G R, Cott J M, Cooper B R, Prange A J, Lipton M A, Plotnikoff N P (1975) Effects of thyrotropin-releasing hormone (TRH) on the actions of pentobarbital and other centrally acting drugs. J Pharmacol Exp Ther 193: 11-22

Brezenoff H E, Vargas H, Xiao Y-F (1988) Blockade of brain M2 muscarinic receptors lowers blood pressure in spontaneously hypertensive rats. Pharmacology 36 : 101-105

Burke R E (1986) The relative selectivity of anticholinergic drugs for the M1 and M2 muscarinic receptor subtypes. Mov Disord 2: 135-144 
Buschke $H$ (1973) Selective reminding for analysis of memory and learning. J Verb Learn Verb Behav 12: 543-550

Decker M W (1987) The effects of aging on hippocampal and cortical projections of the forebrain cholinergic system. Brain Res Rev 12: 423-438

Drachman D A, Leavitt J (1974) Human memory and the cholinergic system. Arch Neurol 30: 113-121

Drachman D A (1977) Memory and cognitive function in man: Does the cholinergic system have a specific role? Neurology 27: 783-790

Faden A I, Jacobs T P, Smith M T (1984) Thyrotropinreleasing hormone in experimental spinal injury: Dose response and late treatment. Neurology 34: 1280-1284

Gibson G, Peterson C, Jenden D J (1981) Brain acetylcholine declines with senescence. Science 213: 674-676

Griffiths E C, Kelly J A, Ashcroft A, Ward D J, Robson B (1989) Comparative metabolism and conformation of TRH and its analogues. Ann NY Acad Sci 5: 217-231

Hasher L, Zacks RT (1979) Automatic and effortful processes in memory. J Exp Psychol (Gen) 108: 356-388

Hefti F, Dravid A, Hartikka J (1984) Chronic intraventricular injection of nerve growth factor elevate hippocampal choline acetyltransferase activity in adult rats with partial septal-hippocampus lesions. Brain Res 293: 303-311

Horita A, Carino M A, Lai H (1986) Pharmacology of thyrotropin-releasing hormone. Annu Rev Pharmacol Toxicol 26: 311-332

Horita A, Carino M A, Zabawska J, Lai H (1989) TRH analog MK-771 reverses neurochemical and learning deficits in medial septal-lesioned rats. Peptides 10: 121-124

Hutson P H, Semark J E, Middlemeiss D N (1990) The TRH analog MK-771 increases acetylcholine release in hippocampus but not striatum of the conscious rat. Neurosci Lett 116: 149-155

Lamour Y, Dutar P, Jobert A (1983) Effects of neuropeptides on rat cortical neurons: laminar distribution and interaction with the effect of acetylcholine. Neuroscience 10: $107-117$

Lamour Y, Senut M C, Dutar P, Bassant M H (1989) Neuropeptides and septo-hippocampal neurons: Electrophysiological effects and distributions of immunoreactivity. Peptides 9: 1351-1359

Lampe TH, Norris J, Risse SC, Owen-Williams E, Keenan $\mathrm{T}$ (1990) Therapeutic potential of thyrotropinreleasing hormone (TRH) and lecithin co-administration in Alzheimer's disease. Neurobiol Aging 384: 346(Abstract)

Lange K W, Rossor M N, Jenner P, Marsden C D (1990) Cholinergic markers in Alzheimer's disease and Parkinson's disease. Neurobiol Aging 384: 273(Abstract)

Lippa A S, Loullis C C, Rotrosen J, Cordasco D M, Critchett D J, Joseph J A (1985) Conformational changes in muscarinic receptors may produce diminished cholinergic neurotransmission and memory deficits in aged rats. Neurobiol Aging 6: 317-323

Manaker S, Eichen A, Winokur A, Rhodes C H, Rainbow TC (1986) Autographic localization of thyrotropin releasing hormone receptors in human brain. Neurology 36: 641-646

Marcyniuk B, Mann D M A, Yates P O (1989) The topography of nerve cell loss from the locus coeruleus in elderly persons. Neurobiol Aging 10: 5-9
Mash D C, Flynn D D, Potter L T (1985) Loss of M2 muscarinic receptors in the cerebral cortex in Alzheimer's disease and experimental cholinergic denervation. Science 228: 1115-1117

Mattila J, Bunag R B (1986) Sympathetic vasoconstrictor and renin secretion caused pressor responses to thyrotropin-releasing hormone in rats. J Pharmacol Exp Ther 238: 232-238

McKhann G, Drachman D, Folstein M, Katzman R, Price D, Stadlan E M (1984) The clinical diagnosis of Alzheimer's disease: Report of the NINCDS-ADRDA work group. Neurology 34: 939-944

Mellow A M, Sunderland T, Cohen R M, Lawlor B A, Hill J L, Newhouse P A, Cohen M R, Murphy D L (1989) Acute effects of high-dose thyrotropin releasing hormone infusions in Alzheimer's disease. Psychopharmacology 98: 403-407

Metcalf G (1982) Regulatory peptides as a source of new drugs: The clinical prospects for analogues of TRH which are resistant to metabolic degradation. Brain Res Rev 4: 389-408

Mewaldt SP, Ghoneim M M (1979) The effects and interactions of scopolamine, physostigmine and methamphetamine on human memory. Pharmacol Biochem Behav 10: 205-210

Mitsumoto H, Salgado E D, Negroski D, Hanson M R, Salanga VD, Wilbur JF, Wilbourn A J, Breur A C, Leatherman J (1986) Amyotrophic lateral sclerosis: effects of acute intravenous and chronic subcutaneous administration of thyrotropin-releasing hormone in controlled trials. Neurology $36: 152-159$

Mohs R C, Davis B N, Johns C A, Mathe A A, Greenwald B S, Horvath T B, Davis K L (1985) Oral physostigmine treatment of patients with Alzheimer's disease. Am J Psychiatr 142: 28-33

Molchan S E, Mellow A M, Lawlor B A, Weingartner H J, Cohen R M, Cohen M R, Sunderland T (1990) TRH attenuates scopolamine-induced memory impairment in humans. Psychopharmacology 100: 84-89

Narumi S, Nagai Y, Miyamoto M, Nagawa Y (1983) Thyrotropin-releasing hormone (TRH) and its analogue (DN-1417): interaction with pentobarbital and choline uptake and acetylcholine synthesis of rat brain slices. Life Sci 32: 1637-1645

Nordberg A, Winblad B (1981) Cholinergic receptors in human hippocampus-regional distribution and variance with age. Life Sci 29: 1937-1944

Okada M (1991) Effects of a new thyrotropin releasing hormone analogue, YM-14673, on the in vivo release of acetylcholine as measured by intracerebral dialysis in rats. J Neurochem 56: 1544-1547

Okuda C, Mizobe T, Miyazaki M (1987) The involvement of central cholinergic mechanisms in cardiovascular responses to intracerebroventricular and intravenous administration of thyrotropin-releasing hormone. Life Sci 40: 1293-1299

Pedigo N W (1988) Pharmacological adaptations and muscarinic receptor plasticity in hypothalamus of senescent rats treated chronically with cholinergic drugs. Psychopharmacology 95: 497-501

Perry EK (1980) The cholinergic system in old age and Alzheimer's disease. Age and Ageing 9: 1-8 
Price D L (1986) New perspectives on Alzheimer's disease. Annu Rev Neurosci 9: 489-512

Reisberg B, Ferris S, De Leon M, Crook T (1982) The Global Deterioration Scale for assessment of primary degenerative dementia. Am J Psychiatr 139: 1136-1139

Rinne J O (1987) Muscarinic and dopaminergic receptors in the aging human brain. Brain Res 404: 162-168

Safer D J, Allen RP (1971) The central effects of scopolamine in man. Biol Psychiatr 3: 347-355

Schwarz R D, Bernabei A A, Spencer C J, Pugsley T A (1990) Loss of muscarinic M1 receptors with aging in the cerebral cortex of Fisher 344 rats. Pharmacol Biochem Behav 35: 589-593

Sitaram N, Weingartner H, Gillin J C (1978) Human serial learning: enhancement with arecholine and choline and impairment with scopolamine. Science 201: 274-276

Sunderland T, Tariot P N, Weingartner H, Murphy D L, Newhouse PA, Mueller E A, Cohen R M (1986) Pharmacologic modelling of Alzheimer's disease. Prog Neuropsychopharmacol Biol Psychiatr 10: 599-610

Sunderland T, Tariot P N, Cohen R M, Weingartner H, Mueller EA, Murphy DL (1987) Anticholinergic sensitivity in patients with dementia of the Alzheimer type and age-matched controls: A dose-response study. Arch Gen Psychiatr 44: 418-426

Suzuki T, Fujimoto K, Oohata H, Kawashima K (1989) Effects of TRH and DN-1417 on high potassium-evoked acetylcholine release from rat basal forebrain slices determined directly by radioimmunoassay. Gen Pharmacol 20: 239-242

Tariot P N, Sunderland T, Weingartner H, Murphy D L, Welkowitz J A, Thompson K, Cohen R M (1987) Cognitive effects of L-deprenyl in Alzheimer's disease. Psychopharmacology 91: 489-495

Thompson J M, Makino C L, Whitaker J R, Joseph J A (1984) Age-related decrease in apomorphine modulation of acetylcholine release from rat striatal slices. Brain Res 299: 169-173

van Kammen D P, Murphy D L (1975) Attenuation of the euphoriant and activating effects of $\mathrm{D}$ - and L-amphetamine by lithium carbonate treatment. Psychopharmacologia 44: 215-224

Wechsler D (1945) Standardized memory scale for clinical use. J Psychol 19: 87-95
Weingartner H, Grafman J, Boutelle W, Kaye W, Martin P R (1983) Forms of memory failure. Science 221: 380-382

Wenk G L, Pierce D J, Price D L, Cork L C (1989) Agerelated changes in multiple neurotransmitter systems in the monkey brain. Neurobiol Aging 10: 11-19

Wesnes K, Warburton D M (1984) Effects of scopolamine and nicotine on human rapid information processing performance. Psychopharmacology 82: 147-150

White P, Goodhardt M J, Keet J P, Hiley C R, Carasco L H, Williams I G, Bowen D M (1977) Neocortical cholinergic neurons in elderly people. Lancet $i$ : 668-671

Whitehouse P J, Au K S (1986) Cholinergic receptors in aging and Alzheimer's disease. Prog Neuropsychopharmacol Biol Psychiatr 10: 665-676

Winer B J (1981) Statistical principles in experimental design (2nd edition). McGraw-Hill, New York

Winokur A, Beckman A L (1978) Effects of thyrotropinreleasing hormone, norepinephrine and acetylcholine on the activity of neurons in the hypothalamus, septum and cerebral cortex of the rat. Brain Res 150: 205-209

Wu C F, Bertolli R, Sacconi M, Pepeu G, Consolo S (1988) Decrease of brain acetylcholine release in freely-moving rats detected by microdialysis. Neurobiol Aging 9: 357-361

Yamamura M, Kinoshita K, Nakagawa H, Ishida R (1991) Pharmacological study of TA-0910, a new thyrotropinreleasing hormone (TRH) analog: effects on experimental memory impairment in mice and rats. Jap J Pharmacol 55: 241-253

Yamazaki N, Nagaoka N, Nagawa Y (1986) Effect of thyrotropin-releasing hormone and its analog DN-1417 on scopolamine-induced impairment of short-term memory in rats. Jap J Psychopharmacol 6: 359-366

Yarbrough GG (1979) On the neuropharmacology of thyrotropin releasing hormone (TRH). Prog Neurobiol 12: 291-312

Zornetzer S (1986) The noradrenergic locus coeruleus and senescent memory dysfunction. In Crook T, Bartus $\mathrm{R} T$, Ferris S, Gershon S (eds), Treatment development strategies for Alzheimer's disease. Mark Powley Assoc., Inc., Madison, CT, pp. 337-359

Zweig R M, Ross C A, Hedreen J C, Steele C, Cardillo J E, Whitehouse P J, Folstein MF, Price DL (1988) The neuropathology of aminergic nuclei in Alzheimer's disease. Ann Neurol 24: 233-242 